\title{
RECONSTRUCTION PLAN OF OTSUCHI TOWN, KAMIHEI COUNTY, IWATE PREFECTURE
}

\author{
Yu NAKAI ${ }^{1}$ \\ ${ }^{1}$ Member of JSCE, Professor, Dept. of Civil Eng., The University of Tokyo \\ (3-1 Hongo 7-chome, Bunkyo-ku, Tokyo 113-8656, Japan) \\ E-mail: yu@ civil.t.u-tokyo.ac.jp
}

\begin{abstract}
This paper reports the drafting process and current outline of the reconstruction plan for Otsuchi Town, Kamihei County, Iwate Prefecture, which suffered devastating tsunami damage caused by the Great East Japan Earthquake.
\end{abstract}

Key Words : Great East Japan Earthquake, reconstruction plan, Otsuchi Town, Iwate Prefecture

\section{INTRODUCTION}

This paper reports the process and outline of the reconstruction plan for Otsuchi Town, Kamihei County, Iwate Prefecture, which suffered devastating tsunami damage caused by the Great East Japan Earthquake on March 11, 2011. The author has been involved in the planning process of the basic reconstruction plan for Otsuchi Town as an external expert; thus, this paper is from the author's point of view.

In the 2011 fiscal year, at the request of the City and Regional Development Bureau of the Ministry of Land, Infrastructure, Transport and Tourism
(MLIT), the author became an Otsuchi Town supervisor-a technical adviser-for basic surveys ${ }^{1)}$ for the reconstruction plan. At the request of the Otsuchi Town government, the author became a member of the Revival and Creation Council, which discusses basic principles of reconstruction, and a coordinator of the Local Reconstruction Council, which discusses the reconstruction plan in each neighborhood.

In the 2012 fiscal year, according to the agreement of the University of Tokyo- to which the author belongs-to support reconstruction efforts of Otsuchi Town, the author provided practical support to materialize the reconstruction plan while remain-

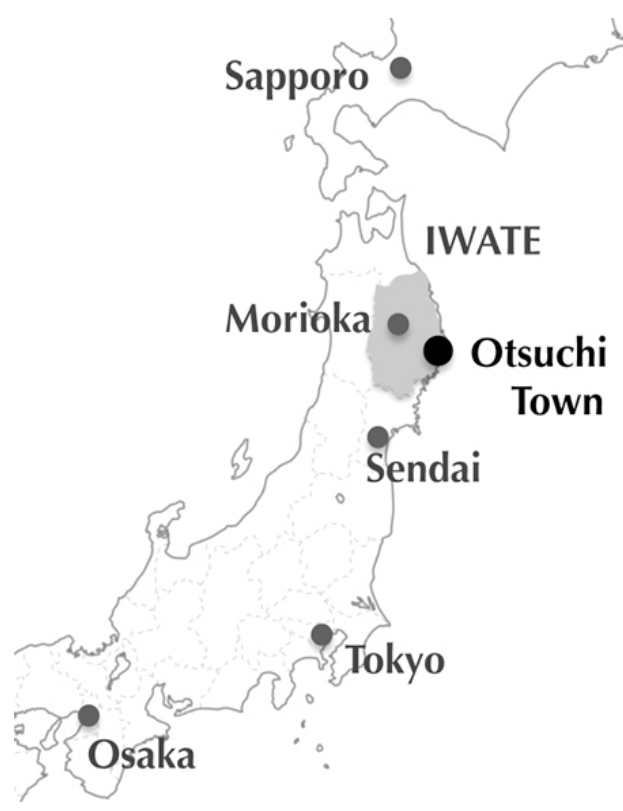

Fig.1 The location of Otsuchi Town.

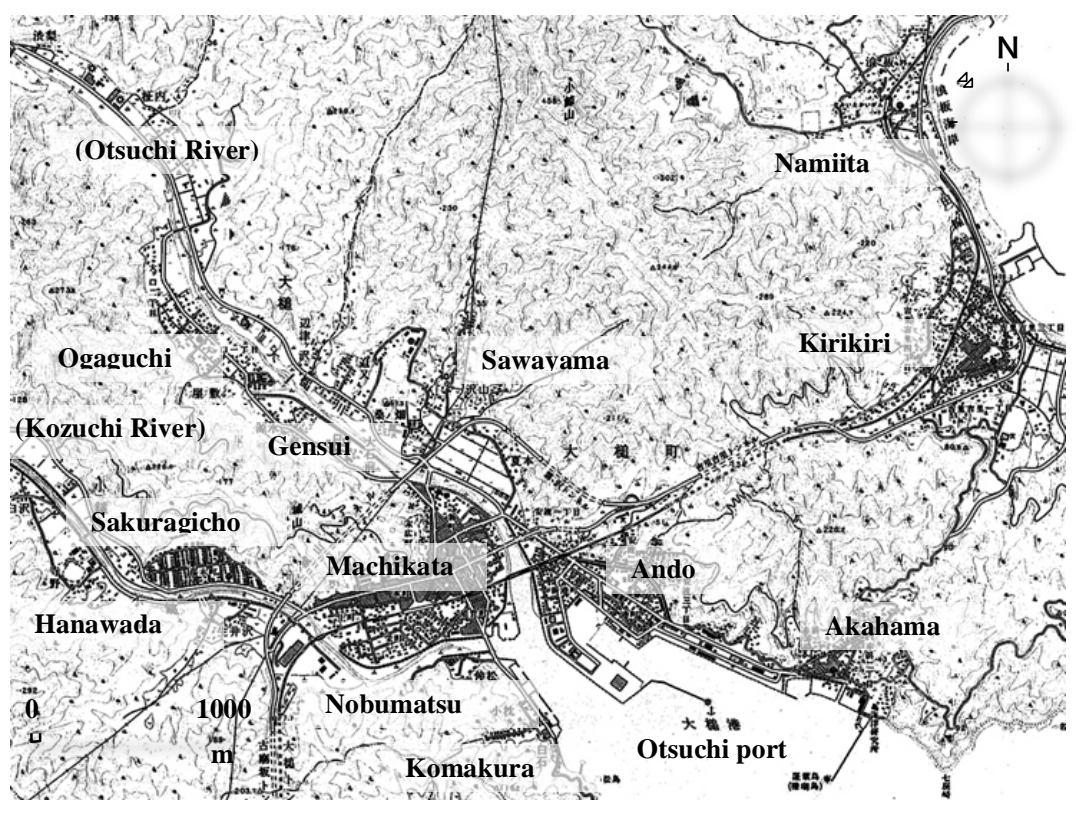

Fig. 2 Community structure of Otsuchi Town. 
ing the coordinator for the Local Reconstruction Council. This report is in terms of these roles of the author. In addition, given the author's area of expertise, this report is limited to the spatial planning aspect of the reconstruction plan.

\section{OUTLINE AND CHARACTERISTICS OF TSUNAMI DAMAGE TO OTSUCHI TOWN}

\section{(1) Outline of tsunami damage to Otsuchi Town}

The giant tsunami that struck Otsuchi Town claimed the lives of 802 people, and 479 people are still missing as of January $31,2012^{2)}$. The number of victims $(1,281)$ is equivalent to 8.4 percent of the population before the disaster $(15,239)$. More than half of the town's senior officials, including the mayor, were swept away by the tsunami; the town's administration basically lost its decision-making capabilities.

The community structure of Otsuchi Town is shown in Fig. . $^{3)}$. The coastal area comprises five major neighborhoods: Machikata—with the largest urban area and the center of the local government-Ando, Akahama, Kirikiri, and Namiita. All of these neighborhoods were entirely destroyed. The inundated area-of which 216.4 ha was completely destroyed, 37.2 ha was half-destroyed, and 19.9 ha was partly destroyed-amounted to $68 \%$ of the area designated for land-use zoning ${ }^{4}$.

Along the Otsuchi and Kozuchi Rivers, which empty into Otsuchi Bay closing in on Machikata, were neighborhoods such as Sawayama, Gensui, and Ogaguchi; Sakuragicho and Hanawada; and Komakura and Nobumatsu. These neighborhoods were also inundated. The maximum inundation depth resulting from the tsunami exceeded $10 \mathrm{~m}$ in many neighborhoods: $10.7 \mathrm{~m}$ in Machikata, $12.9 \mathrm{~m}$ in Akahama, $16.1 \mathrm{~m}$ in Kirikiri, and so on ${ }^{5}$. Important public facilities such as the town hall, hospitals, railway stations, and schools became almost completely unusable because they were either completely destroyed or inundated; the town was, literally, completely destroyed (Fig.3).

\section{(2) Characteristics of tsunami damage in terms of historical landscape}

This section reports on the tsunami damage in terms of the historical landscape. Paying attention to the historical landscape can be expected to provide suggestions for the reconstruction plan.

\section{a) Characteristics concerning the whole affected area}

First, characteristics observed throughout the affected area, not limited to Otsuchi Town, are briefly reported here.

An interesting observation was how shrines survived. This was true not only in Otsuchi Town but also in Onagawa Town, Miyagi Prefecture, and Rikuzentakata City, Iwate Prefecture (which suffered the most appalling damage among the affected communities)—shrines near collapsed buildings survived without collapsing (Fig.4). All of these shrines were located just outside inundated areas. In the plain stretching south from Sendai, there were cases where shrines located on microtopography

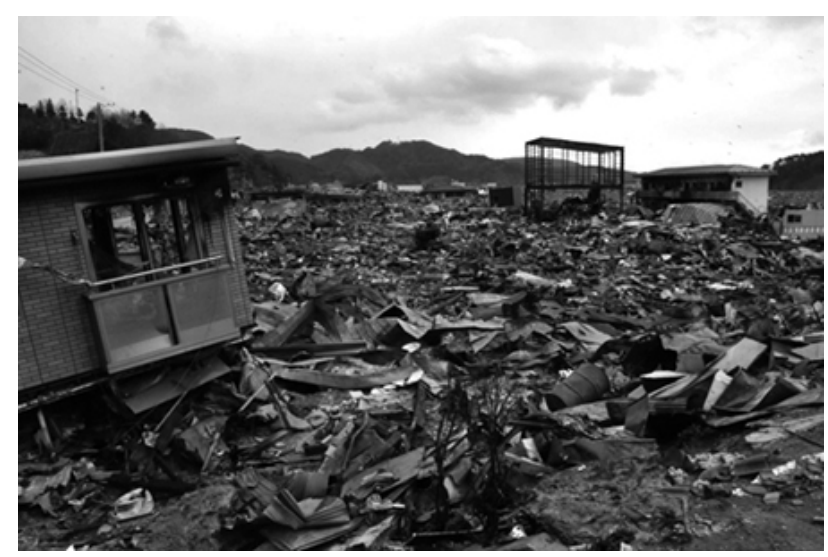

Fig.3 Devastated Machikata neighborhood in Otsuchi Town (photographed by the author).

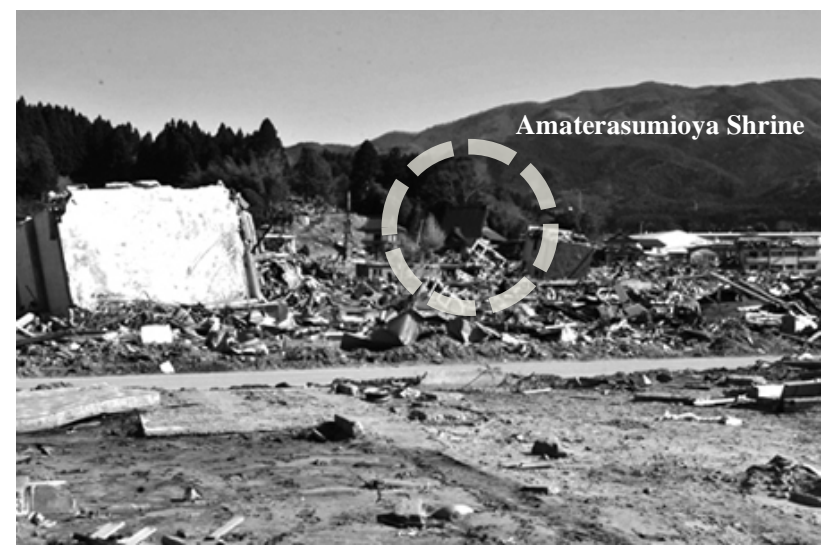

Fig.4 Amaterasumioya Shrine in Rikuzentakata City escaping collapse (photographed by the author).

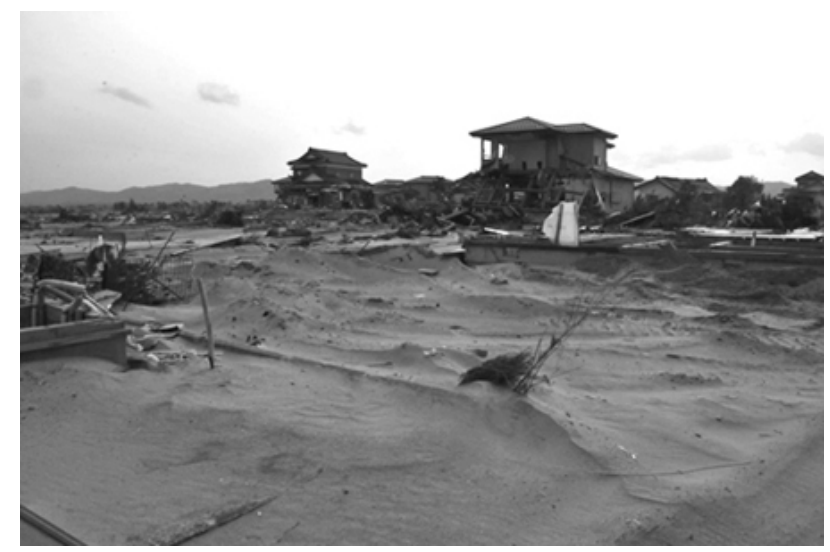

Fig.5 House lots covered with sand after the tsunami in Yamamoto Town, Miyagi Prefecture (photographed by the author). 
around $2 \mathrm{~m}$ above the surrounding land survived despite being submerged. In general, a shrine is a native facility that maintains close relationships with the community's natural conditions, land-use patterns, and lifestyle. Although more than a few shrines were naturally swept away by this tsunami, the particular locations of the shrines may reflect past experiences with tsunamis.

Particularly in the plain south of Sendai, long-standing traditional roads, neighborhoods, and trees around residences clearly maintained their patterns despite being submerged. Because these are generally located on microtopography, small differences in levels of land may have weakened the power of the tsunami waves. Conversely, neighborhoods whose place-names included "shin" (new), such as Shinchi and Shinhama-neighborhoods presumably developed in recent times-were completely destroyed by the relatively strong power of the waves. Furthermore, in Shinchi, Shinchi Town, Fukushima Prefecture, residential areas transformed from wetlands turned into wetlands after the tsunami; in Shinhama, Yamamoto Town, Miyagi Prefecture, residential areas transformed from sands were similarly covered with sand (Fig.5).

Thus, it may be possible that-back when technology for preventing tsunamis with seawalls was not established-traditional locations of neighborhoods, land-use patterns, and locations of infrastructure and public facilities were selected so that they were less susceptible to tsunami damage or they mitigated the extent of the damage.

\section{b) Case of Otsuchi Town}

The characteristics of the tsunami damage to Ot-

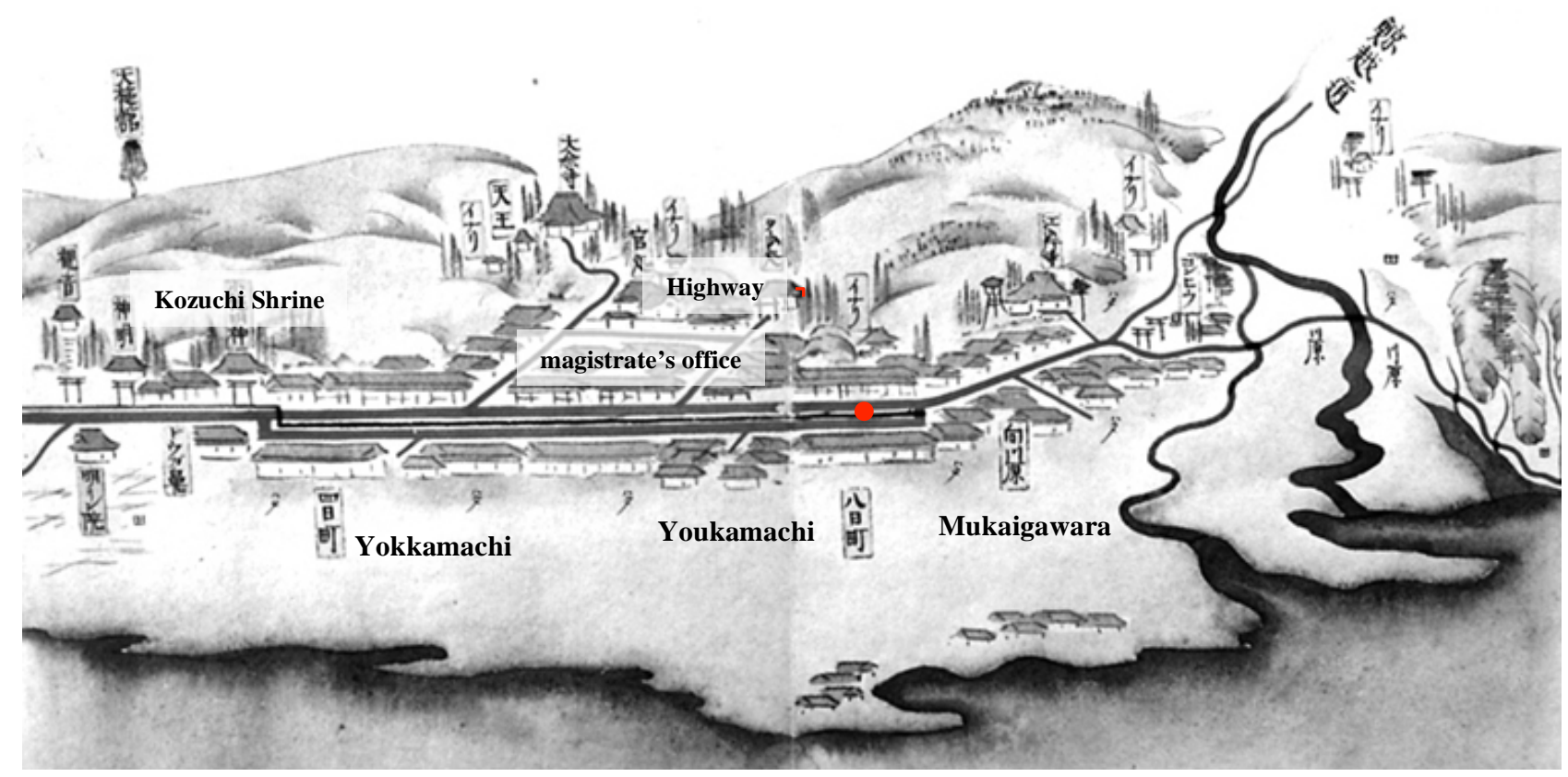

Fig.6 Machikata neighborhood in Otsuchi Town in the Ansei Era (1854-1860).
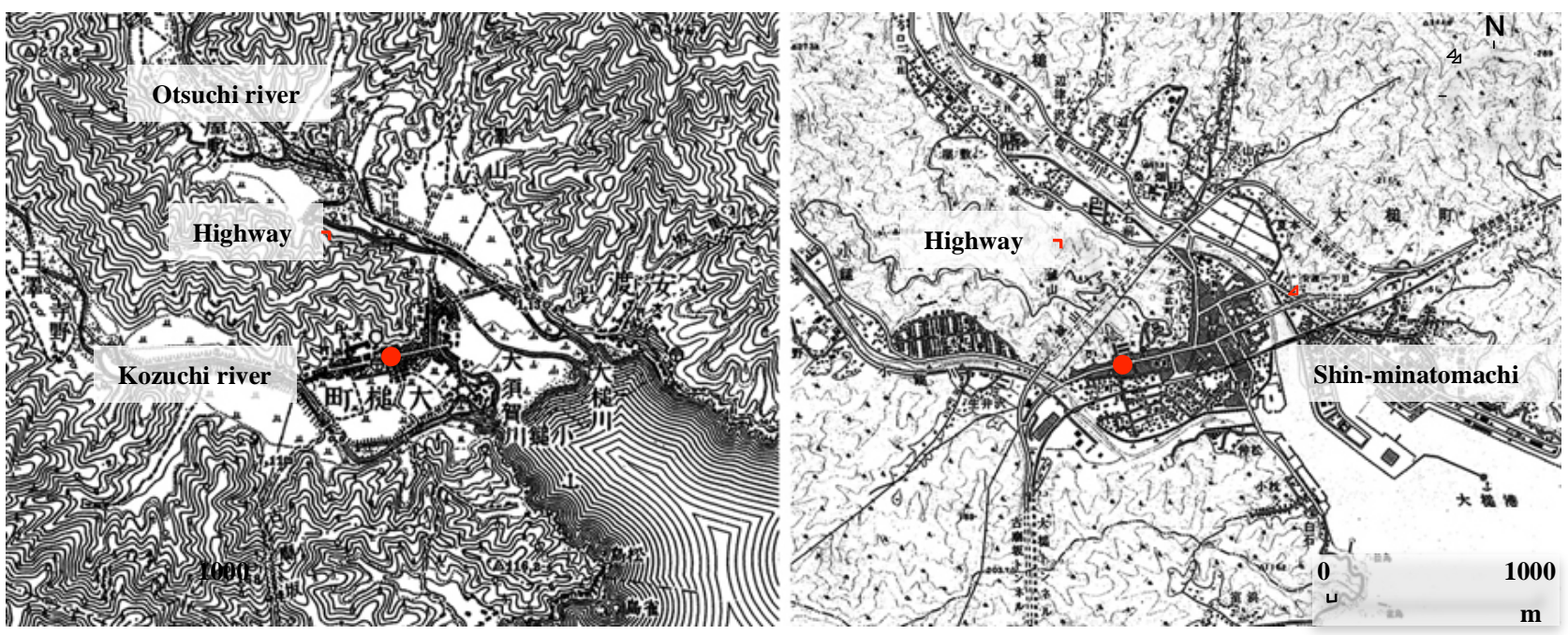

Fig.7 Topographic maps of Machikata neighborhood in 1913 (left) and 2001 (right). 
suchi Town are thus described in terms of the historical landscape.

Fig.6 is a drawing of Machikata in the Ansei Era (1854-1860) in the last days of the Tokugawa government ${ }^{6)}$. The towns of Yokkamachi, Youkamachi, and Mukaigawara were formed on both sides of a highway along mountains with public facilities such as a magistrate's office, temples, and shrines located at the foot of the mountains. As it is concentrated at the foot of the mountains, the structure of the community can be recognized as one that allows people to evacuate easily in the event of a tsunami.

Fig.7 shows topographic maps of Machikata in 1913 and 20017). The 1913 map shows the reconstructed neighborhood after it was damaged by the Meiji Sanriku tsunami in 1896. Its community structure did not differ from that in the Ansei Era. With the highway located in the same place, the urban area was formed along the highway in a concentrated manner, while the area along the Otsuchi and Kozuchi Rivers, which were the paths of the tsunamis, and the area around the estuary were wetlands or paddy fields. Public facilities such as the town hall, schools, and shrines clung to the foot of the mountains as before. The total population of Otsuchi Town was around 9,500 back then.

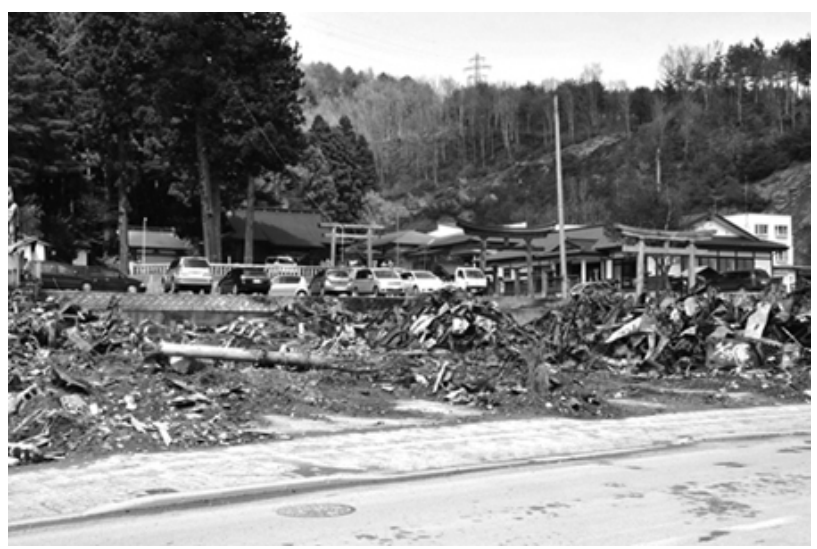

Fig.8 Kozuchi shrine escaping inundation (photographed by the author).

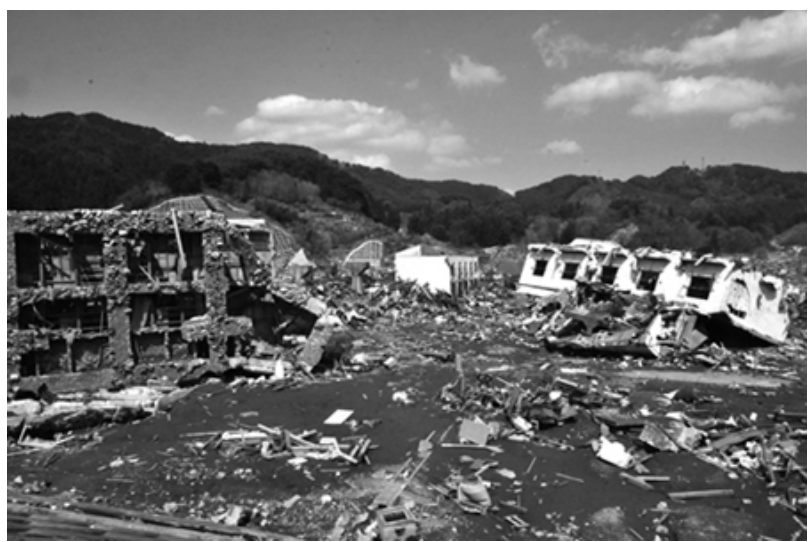

Fig.9 Appalling damage to Shinminatomachi neighborhood (photographed by the author).
In the 1970s, the period of high economic growth after World War II, the urban area rapidly expanded, and the community structure changed. The area along the Otsuchi and Kozuchi Rivers was urbanized; the area around the estuary was reclaimed, and fishery facilities were built. The population of the town soared to approximately 20,000 .

The 2011 tsunami destroyed the entire urban area of Machikata, but Kozuchi Shrine, located in the same place as before, escaped inundation by a hairsbreadth (Fig.8). Conversely, Shinminatomachi, which was urbanized by reclaiming the path of tsunamis during the period of economic growth, was struck with greater power by the waves than other neighborhoods: reinforced concrete buildings toppled, and all the piers of a railway viaduct broke at their bases (Fig.9).

Based on the estimated population before the disaster, the population of Otsuchi Town would decrease to 9,850 in 2035; this population is almost the same as it was around $1913^{8)}$. In this tsunami, 1,281 people lost their lives; in addition, the population exodus accelerated. The town is highly likely to face a greater decrease in population than estimated in the future. Therefore, it is essential to realize an urban structure that enables easy evacuation and lessens the extent of tsunami damage while compacting the urban area in accordance with the decrease in population. For this, the structure of Otsuchi Town in the drawing of the Ansei Era and the 1913 topographic map can be informative in examining the basic land-use patterns and facility locations.

\section{GENERAL PROBLEMS FROM AN EXAMINATION OF THE RECON- STRUCTION PLAN}

This section briefly presents general problems that were recognized from examining the reconstruction plan.

\section{(1) No unifying agency for planning}

First, because the town was lost as a whole, wide-ranging projects have to be pursued simultaneously and comprehensively. Details of projects-from constructing coastal protection facilities to constructing various kinds of infrastructure and public facilities to relocating land uses and residential areas-need to be decided quickly while keeping a holistic view of all these projects.

The problem is that these various kinds of projects cannot proceed under bureaucratic sectionalism as before. For example, the town has no authority to implement projects for the railway, the seawall, the prefectural fishing port, public housing, national and 
prefectural roads constituting the town's main structure, and the like. Projects led by the town are also wide-ranging. Thus, it is in fact extremely difficult to pursue these projects while integrating them into a whole.

The sectional division of labor of the current administration is suitable for dealing with highly functionally differentiated kinds of infrastructure and public facilities as separate components and for functionally sophisticating and optimizing each of them as a separate component. This time, however, when space has to be reorganized both fundamentally and comprehensively, this division of labor of reducing everything to its components is not only ineffective but also rather harmful. The success of this reconstruction plan depends heavily on how to give the plan comprehensiveness and harmony while mitigating the harmful effects of sectionalism.

\section{(2) No methodology for scaling down urban space}

The second problem originates from the fact that the town faces a remarkably declining birthrate and an aging population, which are facilitating a considerable decrease in population. As mentioned earlier, the population of the town is predicted to decrease to at least 9,850 in 2035 , or around $60 \%$ of the pop- ulation before the disaster $(15,239)$. Not only commerce in the town center but also fishery-originally the chief industry-are in remarkable decline; the town was in fact turning into a dormitory town of neighboring Kamaishi. The basic strength required for reconstruction is weakening. Furthermore, as a result of the disaster, there is a fear of a considerable population exodus.

The methodology of modern and current urban planning, however, is essentially based on the tacit assumption that cities expand and grow: urban areas grow spatially; the population increases or becomes concentrated; buildings or facilities become larger; and the scale of the urban economy increases as a whole. Conventional urban planning has the capability to effectively manage cities under these assumptions. However, in the case of Otsuchi Town, the situation is opposite in every respect: the urban area is hollowing; the population is facing a rapid decrease; and it is difficult to expect new large-scale multifamily housing, commercial facilities, or factories to be located there in the future.

Under these circumstances, there is no philosophy or methodology available at present to concentrate the urban area spatially while maintaining a certain level of density - that is, scaling down urban space and returning unneeded land to nature.

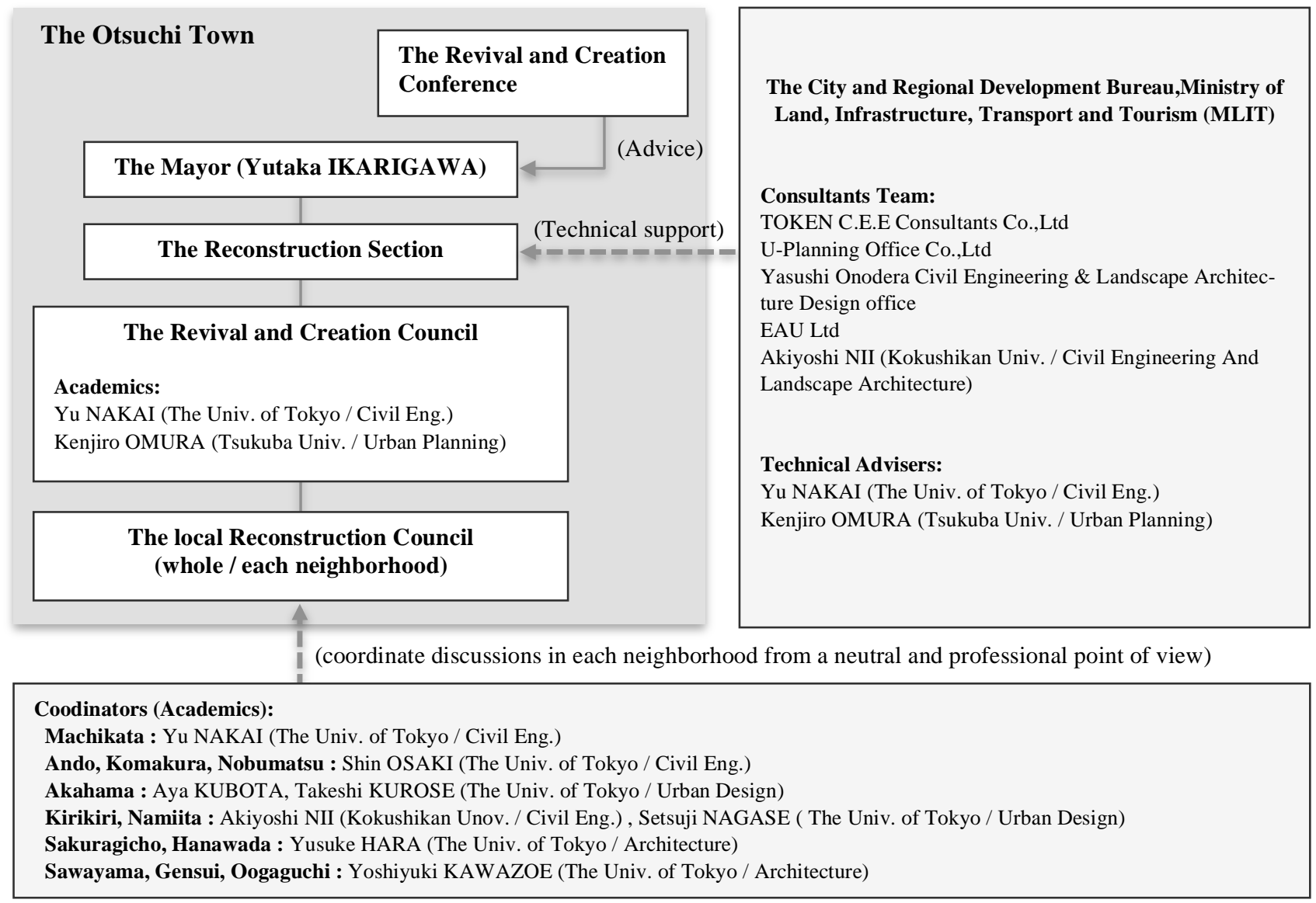

Fig.10 Planning organization of the basic reconstruction plan. 


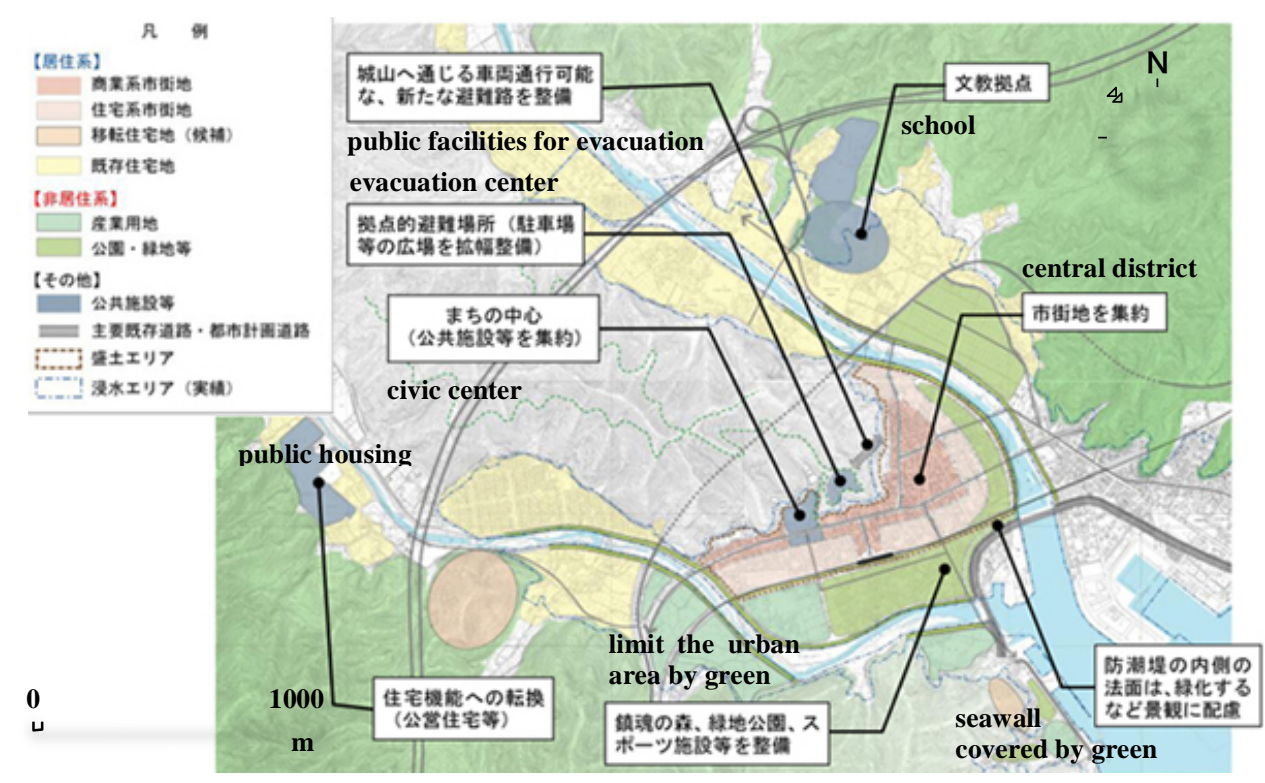

Fig.11 Basic reconstruction plan of Machikata.

\section{(3) Necessity for spatial design using community power}

The third problem is that each affected neighborhood has unique problems, circumstances, historical background, and communal character. Consequently, when pursuing projects, authorities cannot apply methods indiscriminately according to a manual.

In the Sanriku Region, which includes Otsuchi, many neighborhoods still remain that have the potential to maintain a firm and conservative community spirit based on locality. Reconstruction should be pursued using this community power. However, there are almost no effective planning methods currently available to crystallize the community power in a spatial manner. For example, land readjustment is a versatile method for this reconstruction plan. However, it divides all the land into individual lots and places for which the ownership, use, and management all fall under the rights and responsibilities of individuals and authorities. As a result, used wrongly, it could dissolve the community power into individual blocs in this region, where there is still a noticeable traditional spirit of mutual aid.

To avoid this danger, it is necessary to properly plan and design public or common spaces. Importing the methodology of development used for new residential areas on the outskirts of large cities must be avoided at all costs. Whichever method for urban development is used, precise planning and designing of public spaces according to the character of the community is the key to success of the overall plan.

\section{BASIC RECONSTRUCTION PLAN}

\section{(1) Planning process and organization}

The mayor's seat was vacant in Otsuchi Town until the end of August 2011. Although the Reconstruction Preparation Committee was formed in July, substantial planning started after the current mayor, Yutaka Ikarigawa, was elected in September. The draft of basic reconstruction patterns as part of surveys directly conducted by the City Bureau was until then examined.

Early in September 2011, the new mayor presented a bottom-up planning process for the basic plan: each neighborhood was to form a residents' council that would discuss basic principles for the reconstruction plan on the residents' initiative, referring to the draft of reconstruction patterns made by the MLIT team, and that would submit suggestions to the town, which would then decide the basic reconstruction plan within the year. Academics in civil engineering, architecture, and urban planning, including the author, were to coordinate discussions among residents in each neighborhood from a neutral and professional point of view (Fig.10).

After discussions were held at residents' councils every two weeks for about two months, the draft of each neighborhood was prepared at the beginning of December. The town considered these drafts and put together a basic reconstruction plan, which the extraordinary session of the municipal council passed at the end of the year.

\section{(2) Outline of the basic reconstruction plan}

Although discussions about the plan were conducted separately in each neighborhood, certain principles underlie the basic draft from each neighborhood. 


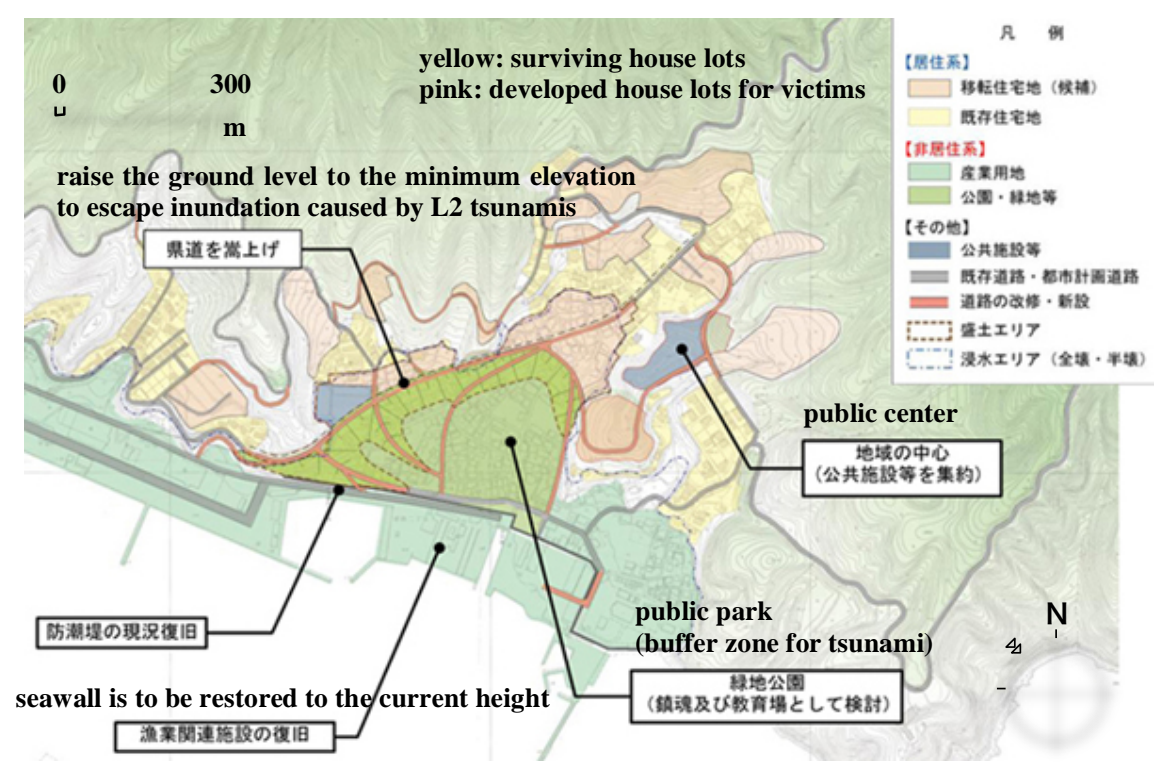

Fig.12 Basic reconstruction plan of Akahama.

First, a decrease in population has to be managed. To maintain a certain degree of strength or liveliness of the community even if the population decreases, the hollowing urban area needs to be concentrated and condensed to maintain or increase the density of exchange between people even if the population decreases.

Second, it is important to not destroy the strong community spirit in each neighborhood, which is characteristic of the Sanriku Region. The aim is to avoid dissolving the connection between people and the land as much as possible; relocating an entire neighborhood to higher ground unrelated to the neighborhood is to be avoided on principle. Reconstruction should be pursued while maintaining the strength of communities and using it as a driving force.

Given these two principles, the basic reconstruction plan of Otsuchi Town is a vision where houses and neighborhoods in the inundated area are relocated outside the area so that they connect with existing unaffected neighborhoods at the foot of the mountains or mingle with them, while the urban area remaining in the inundated area-or forced to remain -is compactly concentrated in areas relatively easy to evacuate.

Fig.11 is an image showing the reconstruction of Machikata ${ }^{9}$. The plan limits the urban area by locating green areas and parks to constitute a green belt. It forms a dense town center along the old highway at the foot of the mountains, from where it is easy to evacuate. By locating public facilities properly, the aim is to enhance the U-shaped community structure as a whole. A seawall that is 14.5 $\mathrm{m}$ high is planned for Machikata; green areas around the urban area are also intended to mitigate the overpowering impression of the seawall as much as possible.

Fig.12 shows the reconstruction plan for Akaha$\mathrm{ma}^{10)}$. The plan is to develop house lots (pink) between surviving lots (yellow); in the coastal area, the lack of house lots is supplemented by raising the ground level to the minimum elevation for the whole neighborhood to escape inundation caused by huge-scale tsunamis such as the last one on 11th March 2011. As a consequence, the neighborhood does not need a huge seawall, so the seawall is to be restored to the current height. This is thought to be an ideal solution: the community is maintained in the same place as much as possible, while the relationship between the neighborhood and sea is not cut off by a huge seawall.

\section{EXAMINATION OF DETAILED SPA- TIAL PLANS}

\section{(1) Planning organization based on WG in each neighborhood}

In the 2012 fiscal year after the basic reconstruction plan was approved, master plans for land readjustment projects were legally decided, and collections were approved by the minister. Concrete spatial plans were then prepared to implement projects. Otsuchi Town was joined by a total of 27 technical support staff members from two prefectures and 18 towns whose terms ranged from 3 months to 1 year.

With the department of urban development leading the overall work, each team responsible for administrative work examined detailed plans in multiple neighborhoods simultaneously to realize the basic plan. For example, the team of land readjustment was in charge of not only the technical aspects 
of land readjustment but also of examining detailed reconstruction plans for the Machikata and Sawayama neighborhoods. Individuals acting as coordinators when the basic reconstruction plan was examined joined the team as advisors. Including consultants in charge of practical work, a working team, called a neighborhood WG, was formed to make a detailed plan for each neighborhood.

\section{(2) Example of a detailed plan: Machikata}

Mayor Ikarigawa's election pledge was "meticulously creating a beautiful town with a view of the sea where people are enticed into taking a stroll." The objective of the basic reconstruction plan is also anchored on this pledge. As an example of spatial plans to realize this planning objective, Fig.13 shows the detailed plan for Machikata ${ }^{11)}$.

a) Concentrating the urban area along the old highway at the foot of mountains

The urban area of Machikata was historically an L-shape along the old highway at the foot of the mountains. The plan follows this historical community structure as well as the scale and shape of the urban area.

To consider evacuation in an emergency, the plan concentrates the urban area within 150-200 m from the foot of the mountains; the urban area is surrounded by the relocation promotion area, which is like a green belt. The playing field on the outskirts of the town is moved to the relocation promotion area, where springs and waterfronts using the many artesian wells characteristic of Machikata are created here and there; combined with the creation of forests, the area is planned to become a lively recreation area.

In addition, by concentrating the commercial function around the L-shaped historical axis as much as possible, the plan aims to form a dense urban area as a center of Machikata.

\section{b) Formation of a road system considering evac- uation}

For evacuation routes toward mountains, the plan is to construct roads $12-15 \mathrm{~m}$ wide at intervals of around $200 \mathrm{~m}$ that are connected with the old highway at right angles. With these new roads in place, residents can reach the foot of the mountains within 5 min from anywhere in the urban area. In addition, the plan specifies some places along the old highway, which are usually where residents stay and work, as important relay points when they evacuate; the plan creates public squares there.

\section{c) Network of public spaces considering both} normal times and emergencies

Many victims who evacuated by car when the earthquake struck got caught in traffic jams and were drowned by the tsunami. In a small urban area with mountains closing in, like Machikata, the fundamental rule is to evacuate on foot as much as pos-

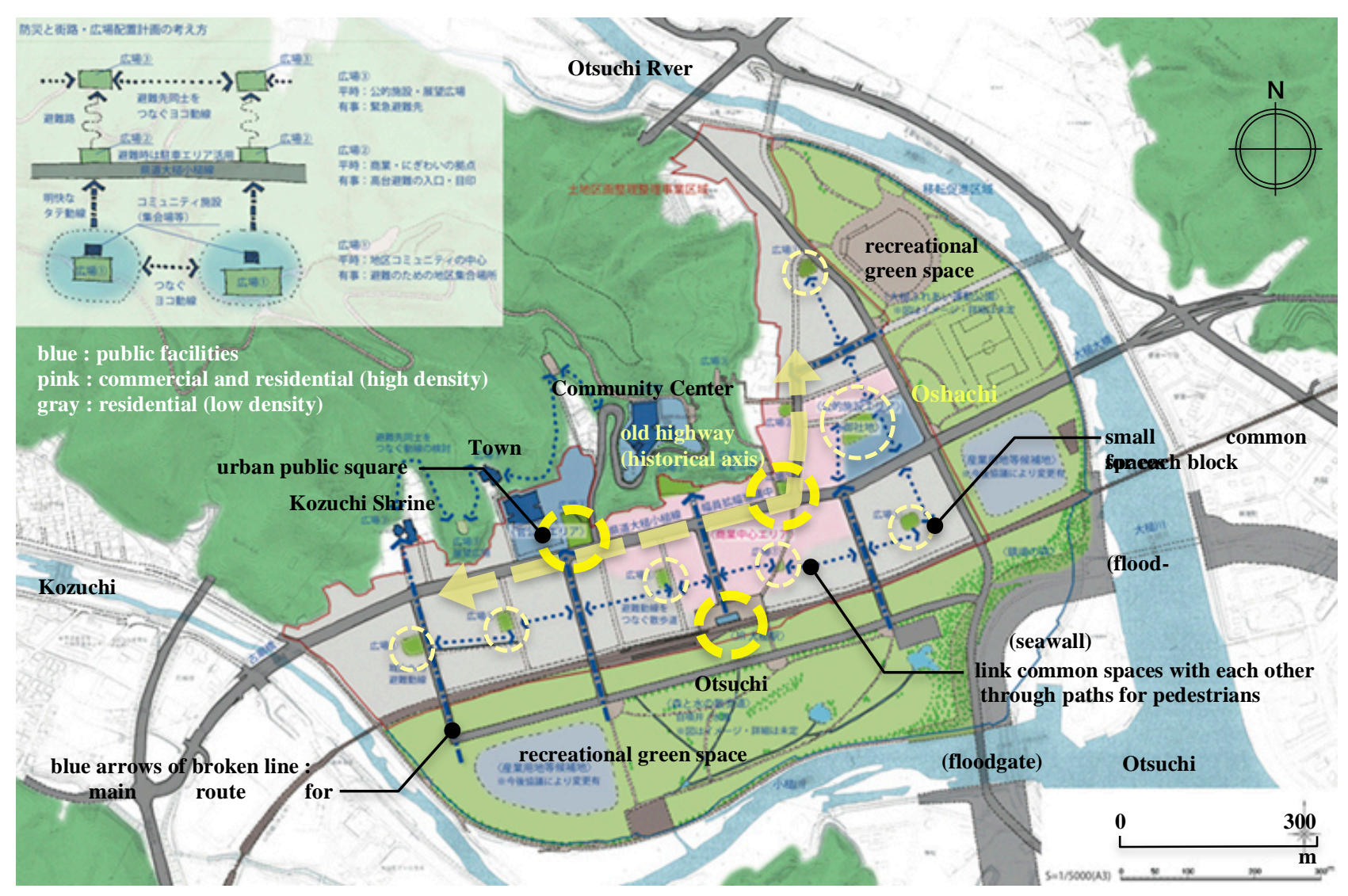

Fig.13 Principle of the spatial plan of Machikata. 
sible. In order to be able to evacuate on foot in emergencies, it is necessary for residents to walk during normal times. Needless to say, improving walkability is effective not only for emergencies but also in normal times to maintain the frequency of exchange between people and a certain degree of liveliness in the town.

According to the plan, the urban area is subdivided into $150 \mathrm{~m} \times 200 \mathrm{~m}$ blocks. Within each block, the plan is to create a square as a common space; the squares are connected with each other by streets or greenways through the block, with priority mainly given to pedestrians. This leads to the creation of promenades linking common spaces.

\section{d) Creating spaces using abundant water}

Machikata is unique in that there are springs-artesian wells-everywhere in the urban area. Representative of these springs is Oshachi, which is to be restored as a core common space for the whole town and combined with public facilities such as a library and community center. In addition, the plan encourages commercial facilities to be located in this space or concentrates them here with the aim of establishing a space symbolic of reconstruction.

Also in squares and common spaces created throughout the town, the plan uses springs, and not only Oshachi, as much as possible; road construction using waterways has been examined in an attempt to enhance the identity of Machikata as being blessed with abundant water.

ACKNOWLEDGMENT: On the initiative of the local government, discussions on the reconstruction plan for Otsuchi Town involved the City Bureau of the MLIT, the Reconstruction Agency, Iwate Prefecture, the Urban Renaissance Agency, TOKEN C.E.E. Consultants-which is in charge of practical work-and academics, including the author. This paper reports the result of those discussions from the author's point of view; all the responsibilities concerning the contents of the paper lies with the au- thor. The author expresses appreciation for those concerned and hopes the reconstruction plan results in an attractive Otsuchi Town as soon as possible.

\section{REFERENCES}

1) The Broad Examination of Urban Reconstruction Patterns in accordance with the Extent of Damage Caused by the Great East Japan Earthquake (No.6), The City and Regional Development Bureau of the Ministry of Land, Infrastructure, Transport and Tourism, March 2012.

2) From the website of Otsuchi Town (http://www.town.otsuchi.iwate.jp/).

3) The author processed the topographic map "Otsuchi" on a scale of 1:25,000 published by the Geospatial Information Authority of Japan in 2001.

4) The Reconstruction Plan of Otsuchi Town after the Great East Japan Earthquake and Tsunami: The Basic Plan (Otsuchi Town, Iwate Prefecture, p.3, December 2011).

5) From the summary list (1/12) in The Broad Examination of Urban Reconstruction Patterns in accordance with the Extent of Damage Caused by the Great East Japan Earthquake (No.6) (the City and Regional Development Bureau of the Ministry of Land, Infrastructure, Transport and Tourism, March 2012).

6) From Sanhei Dochu Map (kept in the Central Community Center of Morioka City).

7) The topographic map "Otsuchi" on a scale of 1:50,000 published by the Land Survey Department in 1923 (left); the topographic map "Otsuchi" on a scale of 1:25,000 published by the Geospatial Information Authority of Japan in 2001 (right).

8) Population Projections by Municipality in Japan (The National Institute of Population and Social Security Research, projections in December 2008).

9) The Reconstruction Plan of Otsuchi Town after the Great East Japan Earthquake and Tsunami: The Basic Plan (Otsuchi Town, Iwate Prefecture, p.61, December 2011).

10) The Reconstruction Plan of Otsuchi Town after the Great East Japan Earthquake and Tsunami: The Basic Plan (Otsuchi Town, Iwate Prefecture, p.66, December 2011).

11) This map was handed out to residents at the meeting of the Local Reconstruction Council of Machikata Neighborhood held on June 30, 2012. This map was made by the author and Hideya Fukushima.

(Received November 12, 2012) 